\title{
Data, not dogma, for ischemic mitral regurgitation
}

\author{
Eric J. Charles, MD, and Irving L. Kron, MD
}

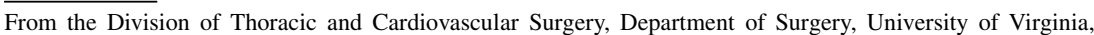
Charlottesville, Va.

E.J.C. is a Cardiothoracic Surgical Trials Network (CTSN) fellow and is supported by the National Heart, Lung, and Blood Institute (project number UM1HL088925).

Disclosures: Authors have nothing to disclose with regard to commercial support.

Received for publication March 23, 2017; accepted for publication March 24, 2017; available ahead of print April $27,2017$.

Address for reprints: Irving L. Kron, MD, Department of Surgery, University of Virginia, PO Box 800679, Charlottesville, VA 22908 (E-mail: ilk@virginia.edu).

J Thorac Cardiovasc Surg 2017;154:137-8

$0022-5223 / \$ 36.00$

Copyright (C) 2017 by The American Association for Thoracic Surgery

http://dx.doi.org/10.1016/j.jtcvs.2017.03.101
}

Historically, the surgical management of ischemic mitral regurgitation (MR) was based on small trials and weak evidence. Few guidelines existed, and published data were observational or underpowered. This uncertainty yielded differences in practice and outcomes. Ischemic MR is a complex disease of the ventricle. The severity of regurgitation can be difficult to diagnose and is subject to changes in fluid status and loading conditions of the heart. The initial cardiac insult, associated structural abnormalities, and characteristics of left ventricular remodeling after myocardial infarction all need to be considered. ${ }^{1}$ These nuances are why data, not dogma, should dictate proper management for ischemic MR.

In this issue of the Journal, Virk and colleagues ${ }^{2}$ present a systematic review and meta-analysis evaluating mitral valve (MV) surgery and coronary artery bypass grafting (CABG) for management of moderate-to-severe ischemic $\mathrm{MR}^{2}{ }^{2}$ Four randomized controlled trials and 15 observational studies that reported mortality data after isolated CABG or CABG plus MV surgery for patients with at least moderate ischemic MR were included. Virk and colleagues ${ }^{2}$ concluded that although there was no increase in perioperative mortality relative to $\mathrm{CABG}$ alone with the addition of $\mathrm{MV}$ surgery and that recurrence of MR was reduced, there was also no reduction in late mortality. Virk and colleagues ${ }^{2}$ included patients with both moderate and severe MR, which is a major limitation of this study. MR exists on a continuum, but moderate and severe regurgitation are distinct physiologic entities.

The findings from this study support the conclusions from the moderate MR trial conducted by the Cardiothoracic Surgical Trials Network (CTSN). ${ }^{3}$ In this trial, mortality was not increased with the addition of MV repair to $\mathrm{CABG}$ for moderate $\mathrm{MR}$, but there was also no improvement in degree of left ventricular reverse remodeling. At 2 years, the addition of $\mathrm{MV}$ repair to CABG did not improve survival and was associated with more neurologic events. ${ }^{4}$ Just because you can repair the MV safely does not mean that you should. On the

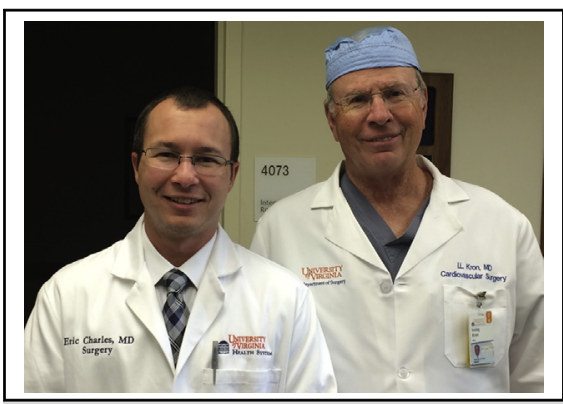

Eric J. Charles, MD (fellow, left) and Irving L. Kron, MD (investigator), Cardiothoracic Surgical Trials Network.

Central Message
High-quality, multicenter, randomized,
controlled trial data from the Cardiothoracic
Surgical Trials Network have changed clinical
practice for moderate and severe ischemic
mitral regurgitation.

See Article page 127.

basis of these data, many of the CTSN investigators now support isolated $\mathrm{CABG}$ for the management of moderate ischemic MR.

The story differs for severe MR. MV repair was historically the default option, but with the results of the CTSN severe ischemic MR trial, replacement now has a place at the table..$^{5}$ In this trial, MV repair was compared with replacement for severe ischemic MR. No differences in left ventricular reverse remodeling or survival at 1 and 2 years were seen. ${ }^{5,6}$ Recurrence of moderate or severe MR was significantly less with replacement; however, a subset of patients who underwent successful repair without recurrence arguably had the best outcomes. Further data are needed to determine who will benefit from repair and who should undergo replacement. Perhaps we may design better repair strategies.

Results of the CTSN ischemic MR trials, as well as many of the studies reviewed in the meta-analysis by Virk and colleagues, ${ }^{2}$ have changed clinical practice. The acquisition of high-fidelity data from well-designed clinical trials allows us to advance the surgical management of cardiac diseases in a meaningful, evidence-based manner.

\section{References}

1. American Association for Thoracic Surgery Ischemic Mitral Regurgitation Consensus Guidelines Writing Committee; Kron IL, Acker MA, Adams DH, Ailawadi G, Bolling SF, Hung JW, et al. 2015 The American Association for Thoracic Surgery consensus guidelines: ischemic mitral valve regurgitation. J Thorac Cardiovasc Surg. 2016;151:940-56 
2. Virk SA, Tian DH, Sriravindrarajah A, Dunn D, Wolfenden HD, Suri RM, et al. Mitral valve surgery and coronary artery bypass grafting for moderate-to-severe ischemic mitral regurgitation: meta-analysis of clinical and echocardiographic outcomes. J Thorac Cardiovasc Surg. 2017;154:127-36.

3. Smith PK, Puskas JD, Ascheim DD, Voisine P, Gelijns AC, Moskowitz AJ, et al. Cardiothoracic Surgical Trials Network Investigators. Surgical treatment of moderate ischemic mitral regurgitation. N Engl J Med. 2014;371:2178-88.

4. Michler RE, Smith PK, Parides MK, Ailawadi G, Thourani V, Moskowitz AJ, et al; CTSN. Two-year outcomes of surgical treatment of moderate ischemic mitral regurgitation. N Engl J Med. 2016;374:1932-41.
5. Acker MA, Parides MK, Perrault LP, Moskowitz AJ, Gelijns AC, Voisine P, et al; CTSN. Mitral-valve repair versus replacement for severe ischemic mitral regurgitation. N Engl J Med. 2014;370:23-32.

6. Goldstein D, Moskowitz AJ, Gelijns AC, Ailawadi G, Parides MK, Perrault LP, et al. CTSN. Two-year outcomes of surgical treatment of severe ischemic mitral regurgitation. $N$ Engl J Med. 2016;374:344-53.

7. Kron IL, Hung J, Overbey JR, Bouchard D, Gelijns AC, Moskowitz AJ, et al; CTSN Investigators. Predicting recurrent mitral regurgitation after mitral valve repair for severe ischemic mitral regurgitation. J Thorac Cardiovasc Surg. 2015; 149:752-61.e1 